\title{
Genetic variation in egg dimensions in natural populations of the Great Tit
}

\author{
A. J. Van Noordwijk ${ }^{1,2}$, L. C. P. Keizer ${ }^{1}$, J. H. Van Balen ${ }^{2}$ \& W. Scharloo' \\ ${ }^{1}$ Department of Population and Evolutionary Biology, University of Utrecht, Padualaan 8, $3584 \mathrm{CH}$ \\ Utrecht, The Netherlands \\ 2Institute for Ecological Research, Kemperbergerweg 67,6816 RM Arnhem, The Netherlands
}

\begin{abstract}
Length and breadth of eggs were measured in ringed populations of the Great Tit. During a part of the study volume and weight were also measured, but this did not give additional information, viz. variation in specific weight of fresh eggs and deviations from calculated volume were within the limits of precision. Only in small eggs are length and breadth positively correlated.

In two populations, a major part (60-80\%) of the variation in the clutch means of egg length, egg breadth, shape index and egg volume is only found between clutches of different females. The absence of correlation between different female partners of one male and the similarity of female repeatability to heritability estimates based on daughter-mother regression lead to the conclusion that $60-80 \%$ of the variation in egg dimensions is genetic.

The implications for a potential rapid response to selection resulting in a micro-evolutionary change are discussed.
\end{abstract}

\section{Introduction}

Genetic variation, as revealed by electrophoretic techniques, is omnipresent in natural populations (review, Lewontin, 1974). However it is unresolved whether this protein variation is representative for the genome as a whole, and its functional significance is still rather obscure. Therefore, genetic studies on quantitative traits with adaptive significance in natural populations are necessary to obtain understanding of the extent of genetic variability that is available for genetic adaptation. The dimensions of bird eggs are suitable traits for such a study. In a study of egg dimensions most of the complications involved in the assessment of the relative importance of genetic variation can readily be investigated. It is possible to study genotypeenvironment interaction and the effect of nonrandom distribution of genotypes over environments in a natural environment. This allows predictions of potential rates of microevolutionary change. That such changes have occurred is shown by a study of egg collections (Väisänen, 1969).

In all strains of poultry the heritability values obtained for egg weight and egg breadth are among the highest of all investigated traits (Baker, 1960; Festing \& Nordskog, 1966; Jaffé, 1965; Romanoff \& Romanoff, 1949). It is not possible, however, to make predictions on the presence of genetic variation in natural populations from heritability estimates obtained in poultry. There are two important differences between estimates from domesticated and natural populations, and these have opposite effects. The control of the breeding environment in poultry will increase the proportion of variation that is genetic, while the long history of directional selection for egg weight may have reduced the amount of genetic variation.

There are several aspects of the life-history of a species that will have consequences for the selective

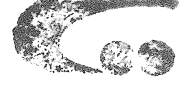

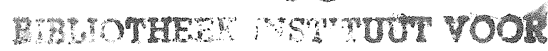

OWOROC NDEROER

Kemperbergerweg $6 \%$

ARNHEN
Bibliotheek sep. No. Naturibeheer 
forces operating on egg size. Clutch size, altricial versus precocial strategy and the presence or absence of hatching asynchrony are probably the most important ones. The availability of food and especially the variation in this availability can be seen as the key factor determining the optimal reproductive strategy (Lack, 1968).

The Great Tit (Parus major L.) is an altricial passerine weighing ca. 16-20 g, which lays first clutches of ca. 7-12 eggs of 1.5-1.8 g. Only in later clutches do eggs hatch asynchronously. This species has been the object of several long-term population studies, in which all nestlings were ringed and their parents were identified (Van Balen, 1973; Dhondt, 1970; Kluyver, 1951; Lack, 1966; Perrins, 1979).

These data make it possible to give heritability estimates for traits such as clutch size and date of laying in a natural environment (Van Noordwijk et al., 1980, 1981a, b).

In the populations studied at the Institute for Ecological Research at Arnhem egg measurements were made in 1977, 1978 and 1979.

In this paper we will first examine the relationship of length, breadth, shape, volume and weight. Then we will demonstrate that relatives show a strong resemblance in their egg characteristics and that this resemblance is mostly genetic. Variation between eggs within a clutch will be treated elsewhere (Van Noordwijk et al., in prep.).

\section{Study areas and general methods}

Four populations of the Great Tit are studied at the Institute for Ecological Research from 1955 onwards. Two populations inhabitat mature oakwood on rich soil (Liesbos and Oosterhout), but these provide insufficient numbers for genetic analyses. Both other populations (Hoge Veluwe and Vlieland) live in pine plantations and mixed woods on poor soil. Hoge Veluwe is a part of a much larger wooded area in the centre of the Netherlands. Vlieland is one of the Dutch Wadden islands; the whole Great Tit population on the island is studied. For details about the study areas the reader is referred to Van Balen (1973) and Kluyver (1971).

Virtually all Great Tits in the study area nest in boxes. Nestboxes are provided in excess and are inspected regularly during the breeding season. Nestlings are ringed with a standard bird ring with a unique number, and the female and the male parent are caught and identified while feeding nestlings of 6-12 days old.

Several types of clutches are distinguished: first clutches, repeat clutches (any clutch following a clutch which produced no fledglings) and second clutches, following a successful first, or occasionaly, following a successful repeat clutch. The normal first clutch contains 7-12 (exceptionally 5-15) eggs, laid at a rate of one egg per day; incubation is started when the clutch is complete and takes 13-14 days. The nestling period amounts to 19-20 days. These are approximate values only (see Kluyver 1951; Van Balen, 1973 and Kluyver et al., 1977).

On Vlieland a substantial number of pairs are known to be related (van Noordwijk \& Scharloo, 1981). While the numbers were too small to investigate an effect of inbreeding on egg dimensions, they might effect the heritability estimates, hence cases with $\mathrm{F}>1 / 16$ were excluded.

\section{Relations between egg traits}

\section{Introduction}

Several characters can be measured. To prevent interference with the long-term population study, we limited ourselves to non-destructive methods. This leaves properties such as length, breadth, weight and volume that can be measured and properties like shape and specific weight that can be calculated from them.

A study of the patterns in which these variables are correlated may suggest ways in which physiological processes come to expression. For instance, if the breadth of an egg is determined by the anatomy of the female and the egg volume by her physiology, egg length will represent the proportion between these two traits. This led us to study not only length and breadth as such, but also different combinations of these parameters, such as volume and shape. In poultry all traits mentioned above (review in Romanoff \& Romanoff, 1949) can successfully be selected for. 


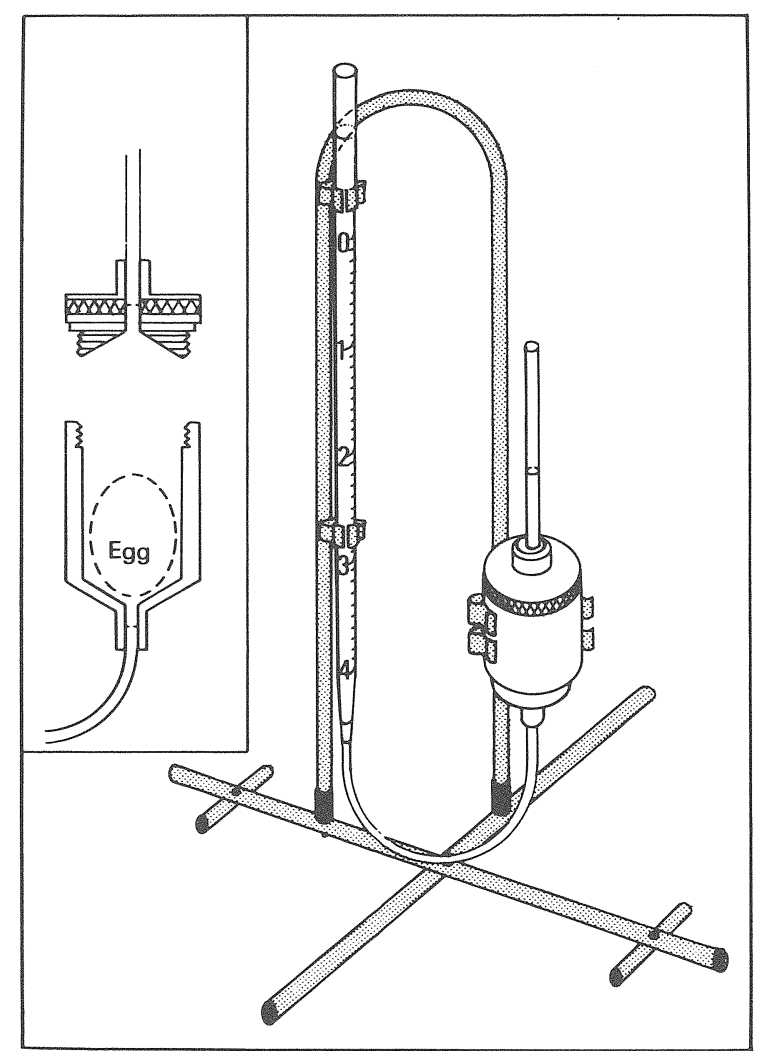

Fig. 1. The apparatus used for measuring egg volumes.

\section{Methods}

The maximum length and breadth were measured with sliding calipers with an accuracy of $0.1 \mathrm{~mm}$. Differences between observers are less than $0.1 \mathrm{~mm}$ and are thus negligible. Eggs that had already been incubated were not weighed. As a consequence very few last eggs were weighed. In 1977 and 1978 we used a simple beam balance and small weights, in 1979 a portable electronic balance was used; both had a precision of $20-30 \mathrm{mg}$. We found none of the published methods to measure volumes practical in the field with eggs of about 1.5 ml (Barth, 1953; Baten \& Henderson, 1941; Langvatn, 1972).

We measured egg volume in the apparatus shown in Figure 1. By moving the pipette up and down the waterlevel was brought to a fixed level in a narrow tube above the chamber. After reading the volume the level was lowered, the egg was put into the chamber and a second reading was made.

A standard calibrated pipette of $5 \mathrm{ml}$ (in $0.05 \mathrm{ml}$ ) was used, by intrapolation an accuracy of 0.01-0.02 $\mathrm{ml}$ was achieved. No effect on hatchability was noted in any stage of incubation, but no eggs within a day of hatching were measured.

\section{Results}

Volume

Several formulae have been suggested to calculate egg volume from egg length and breadth. Nearly all contain length $\times$ breadth $^{2}\left(\mathrm{LB}^{2}\right)$ (see e.g. Baten \& Henderson, 1941; Hoyt, 1976; Stonehouse, 1966). Although breadth is less variable its correlation with measured volume is much stronger than that for length (Fig. 2, Fig. 3). The correlation between measured volume and $\mathrm{LB}^{2}$ is very high $(\mathrm{r}=$ 0.987 for 1252 eggs from 128 clutches from Hoge Veluwe 1978). No deviations from linearity were found. The regression equation was: Volume $=$ $0.495 \mathrm{LB}^{2}+0.017$ with a standard error of 0.012 . In a few clutches the measured volume was consistently above or below the regression line indicating a difference in curvature (see Figure 4 for 9 clutches from Liesbos 1977). Because this variation in shape hardly exceeded the detection

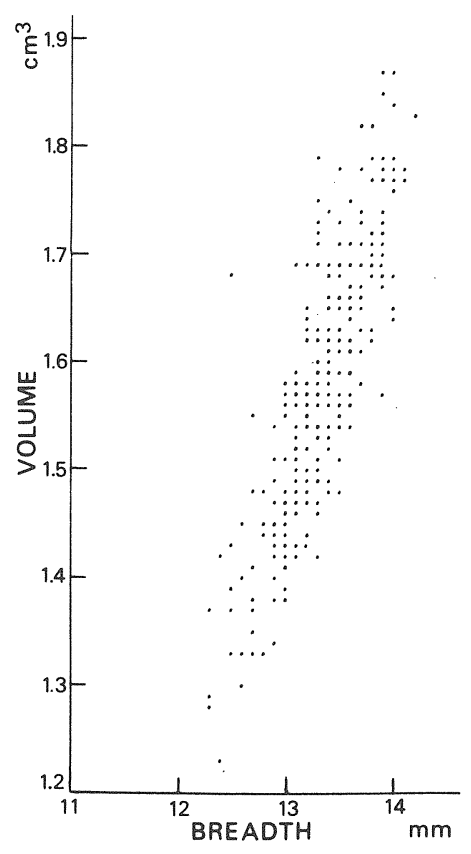

Fig. 2. The relation between breadth and measured volume in eggs from Hoge Veluwe in 1978. Each point represents a combination observed in one or more eggs. 


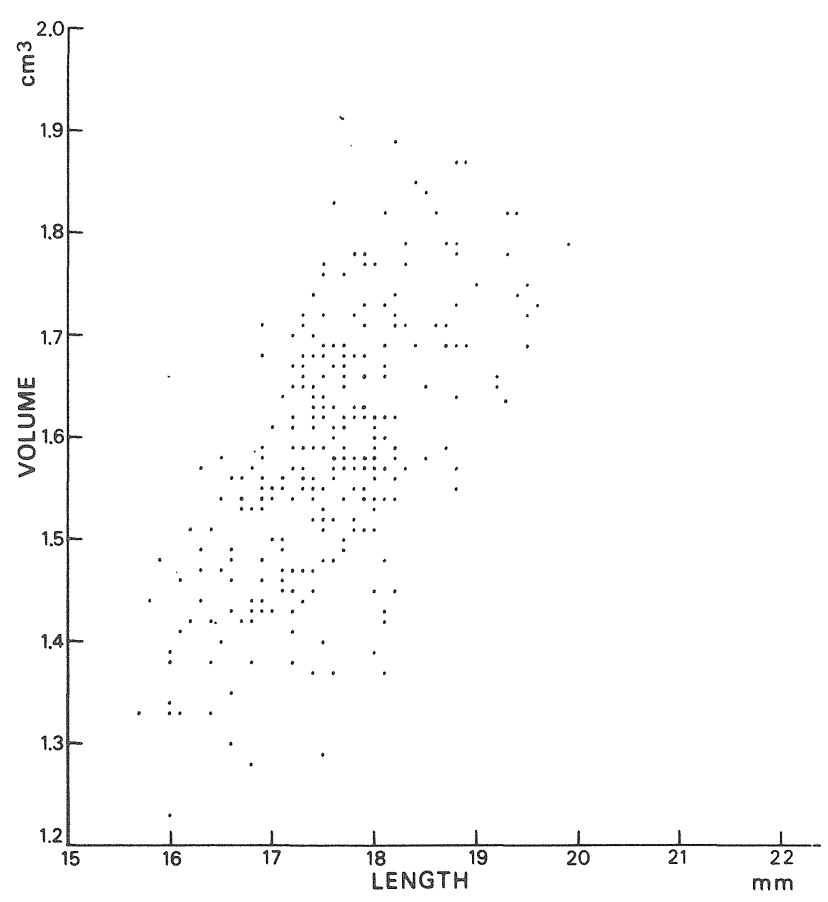

Fig. 3. The relation between length and measured volume. $\mathrm{Cf}$. also Fig. 2.

limit, it was not pursued. The ratio of $\mathrm{LB}^{2} /$ volume would be a good index for the pointedness of the egg, being high in pear shaped eggs and low in more spherical eggs.

\section{Weight}

The specific weight decreases during incubation. In fresh eggs, weight and volume are strongly correlated. In Figure 5 the regression of weight on

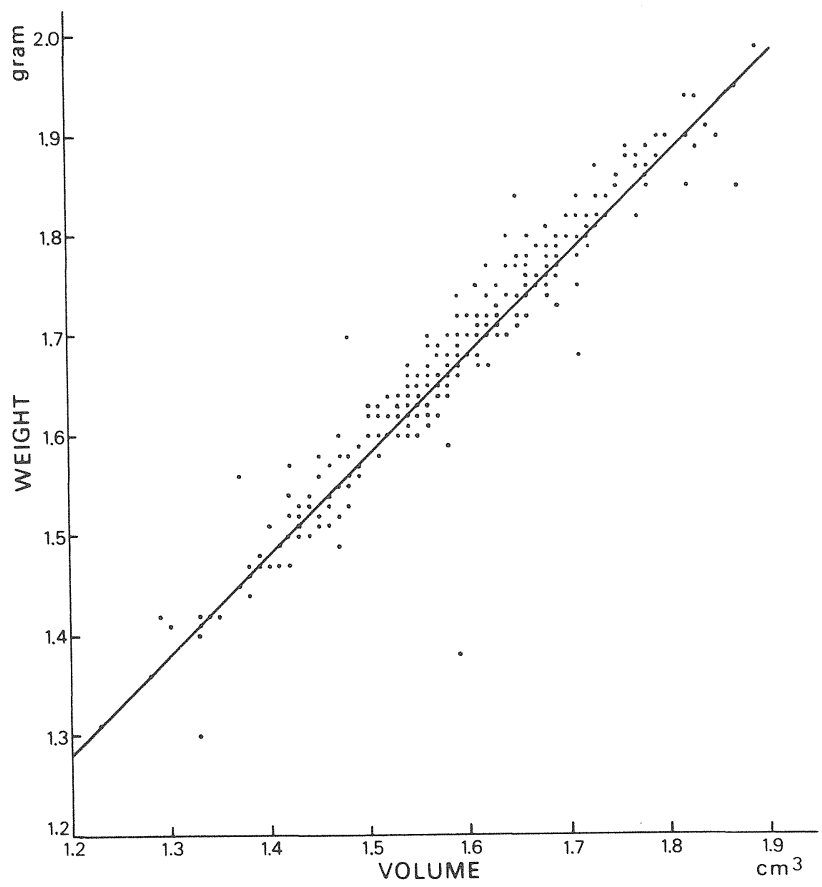

Fig. 5. The relation between fresh weight and measured volume in 286 eggs from Hoge Veluwe 1978. The regression equation is Weight $=1.007$ Vol. $\left(\right.$ in $\left.\mathrm{cm}^{3}\right)+0.073 \mathrm{~g} ; \mathrm{r}=0.97$; standard error of slope $=0.016$.

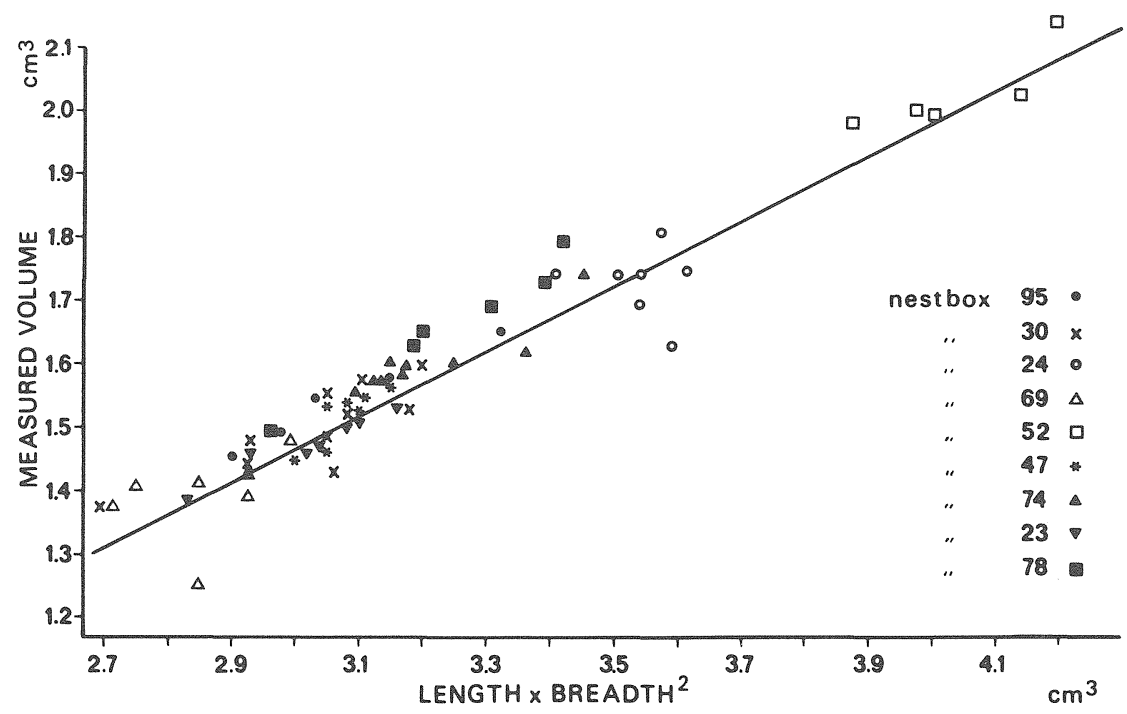

Fig. 4. The relation between measured volume and calculated volume index $\left(\mathrm{LB}^{2}\right)$ for eggs from 9 clutches in Liesbos 1977 . Every clutch has a different symbol. The regression equation is $\mathrm{Vol}=0.51$ L.B. ${ }^{2}-5.24 \mathrm{~mm}^{3} ; \mathrm{r}=0.96$. 


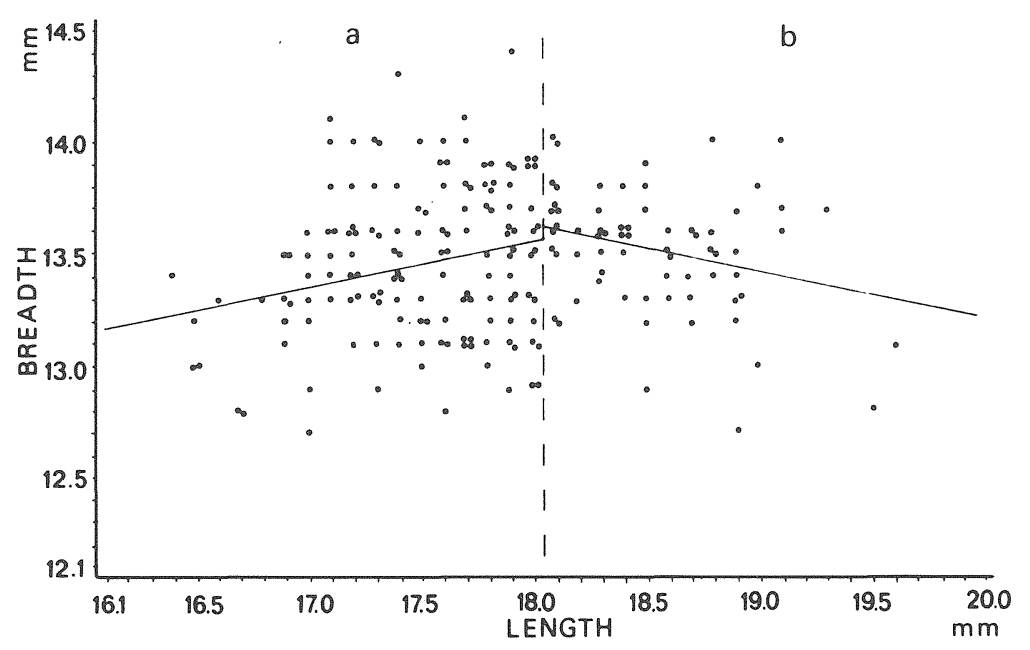

Fig. 6. The relation between egg length and breadth. Liesbos 1977. Regression for eggs with length $\leqq 18 \mathrm{~mm}: \mathrm{B}=0.193 \mathrm{~L}=10.1 \mathrm{~mm}$;

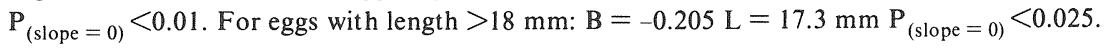

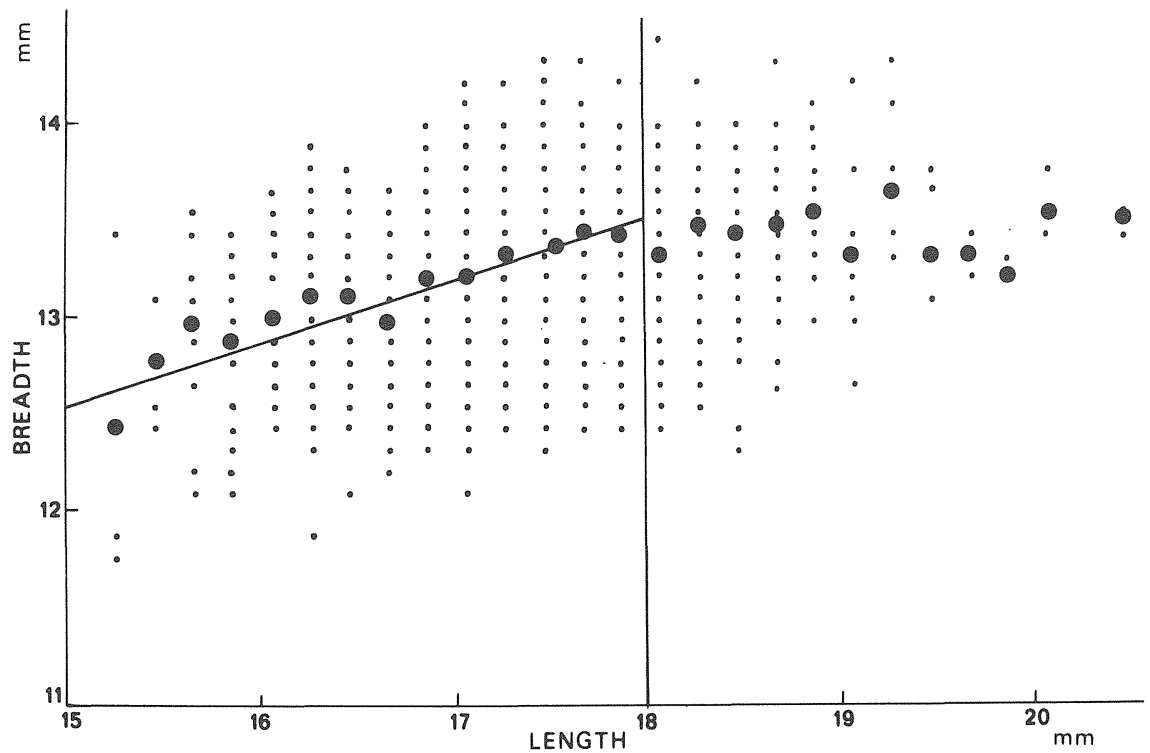

Fig. 7. The relation between egg length and breadth. Hoge Veluwe 1978. Regression of mean breadth per length class (heavy dots) on length for eggs with length $\geqq 18 \mathrm{~mm}$.: $\mathrm{B}=0.315 \mathrm{~L}+7.25 \mathrm{~mm}, \mathrm{P}_{\text {(slope }=0)} \approx 0.5$.

volume is given for 286 eggs from 42 clutches. There are some differences in specific weight between females, as in other species (review Baker, 1960). However, these variations are too close to the limits of precision to justify further analysis in this study. A relation between weight and $\mathrm{LB}^{2}$ includes both variation in specific weight and in pointedness between females. However, these variations in specific weight and pointedness are much smaller than the differences in size between eggs. This means that all types of measurements can be converted into each other with little error.

\section{Linear measurements}

Length and breadth can be determined easily and accurately. In all species investigated the coefficient of variation of breadth is less than that of length (e.g. Koskimies, 1957; Manning, 1978; Myhrberget, 
1977; Nice, 1937; Svensson, 1978 and Väisänen, 1969). Some ratio of length and breadth is widely used as a parameter for egg shape: $100 \times \mathrm{B} / \mathrm{L}$ or $100 \times \mathrm{L} / \mathrm{B}$. It is easily seen that if length and breadth are positively correlated, egg shape will be more constant than egg volume and vice versa if they are negatively correlated. It seems (Fig. $6 \&$ 7) that the relationship between length and bread th varies with egg size. Among the smaller (shorter) eggs there is a positive correlation between length and breadth. Among the longer eggs we find no or even a negative correlation between length and breadth. The same pattern is observed for the within clutch correlation, positive correlation in clutches with small eggs and negative in clutches with large eggs. As a consequence there is a correlation between egg volume and egg shape, small eggs being more spherical than large ones.

\section{Conclusions}

Given the precision of the methods used, no additional information is obtained from directly measured volumes or egg weights. Therefore, in the subsequent analysis volumes calculated from length and breadth will be used as a parameter for egg mass. The dependence of the shape index of calculated volume on length or breadth alone is not simple.

\section{Genetic variation}

\section{Introduction}

Only the basic methods of quantitative genetics (see Falconer, 1960) can be used. A number of the basic assumptions will be tested in explicit form.

A first indication of genetic variation may be obtained from the repeatability, i.e. from a comparison of variation between clutches of the same and of different females. It gives an idea about the importance of temporal environmental variation. This can be done by comparing eggs in first and second clutches within years and by comparing the same type of clutch in different years.

A comparison of the repeatability with the regression of daughters on mothers gives information on the possibility that other factors, e.g. conditions during growth of the female instead of genetic variation are important factors in the individual constancy.

The distance moved between breeding sites in successive years is small, especially in males (Kluyver, 1951; Webber, 1975). Therefore the correlation between successive female mates of a single male ('repeatability of males') is a measure of the importance of spatial environmental variation in the study area at the time of laying. However such a correlation could also arise from assortative mating, or when successive female partners of a male have a similar site preference. The correlation of egg dimensions of partners of fathers and sons gives similar information.

There are four methods to characterize the average shape and egg volume of a clutch. One may either calculate the shape and volume of individual eggs, and then take the average, or calculate mean values from the mean length and breadth. Instead of the mean the median may be used. This has the advantage that the median is less sensitive to rare events with a strong effect. In general the withinclutch variance is largely determined by one or two exceptionally small eggs. All heritability and repeatability estimates were made using the clutch median, where shape and volume were calculated for individual eggs.

Table 1 . Repeatability values.

N Length Breadth Shape Volume

\begin{tabular}{|c|c|c|c|c|c|}
\hline \multicolumn{6}{|l|}{$\begin{array}{l}\text { A. Hoge Veluwe } \\
\text { o repeatability }\end{array}$} \\
\hline 1977 first-second & 27 & 0.68 & 0.62 & 0.79 & 0.57 \\
\hline 1978 first-second & 26 & 0.80 & 0.72 & 0.93 & 0.67 \\
\hline 1979 first-second & 44 & 0.74 & 0.46 & 0.77 & 0.54 \\
\hline first ' 77 - first ' 78 & 32 & 0.79 & 0.59 & 0.88 & 0.59 \\
\hline first ' 78 - first ' 79 & 27 & 0.81 & 0.79 & 0.82 & 0.80 \\
\hline \multicolumn{6}{|l|}{$\hat{o}$ repeatability } \\
\hline first $77-78$ with diff. +9 & 18 & 0.08 & 0.19 & 0.13 & 0.12 \\
\hline first $78-79$ with diff. $q$ & 12 & -0.30 & -0.36 & -0.32 & -0.31 \\
\hline \multicolumn{6}{|l|}{ B: Vlieland } \\
\hline 1977 first-second & 18 & 0.82 & 0.62 & 0.68 & 0.72 \\
\hline 1978 first-second & 20 & 0.83 & 0.19 & 0.92 & 0.39 \\
\hline 1979 first-second & 31 & 0.45 & 0.23 & 0.84 & 0.09 \\
\hline first ' 77 - first ' 78 & 24 & 0.73 & 0.51 & 0.77 & 0.58 \\
\hline first ' 78 - first ' 79 & 18 & 0.72 & 0.76 & 0.90 & 0.65 \\
\hline \multicolumn{6}{|l|}{$\widehat{o}$ repeatability } \\
\hline first $77-78$ with diff. $q$ & 7 & 0.16 & 0.03 & 0.02 & 0.12 \\
\hline first $78-79$ with diff. +9 & 7 & 0.09 & 0.28 & 0.27 & 0.13 \\
\hline
\end{tabular}


Table 2. Heritability values ( \pm s.e.) based on twice the offspring-single parent regression.

\begin{tabular}{lccccc}
\hline & $\mathrm{n}$ & Length & Breadth & Shape & Volume \\
\hline $\begin{array}{l}\text { A. Hoge Veluwe } \\
\text { from mother-daughter } \\
\text { (mean/individual) }\end{array}$ & 60 & $0.58 \pm 0.28$ & $0.80 \pm 0.24$ & $0.94 \pm 0.32$ & $0.66 \pm 0.24$ \\
$\quad \begin{array}{l}\text { from mother-daughter } \\
\text { all combinations }\end{array}$ & 93 & $0.64 \pm 0.24$ & $0.80 \pm 0.22$ & $1.10 \pm 0.28$ & $0.64 \pm 0.20$ \\
$\begin{array}{l}\text { first clutches only } \\
\text { from mother/daughter }\end{array}$ & 142 & $0.96 \pm 0.20$ & $0.90 \pm 0.16$ & $1.08 \pm 0.20$ & $0.86 \pm 0.18$ \\
$\begin{array}{l}\text { all combinations } \\
\text { first \& second clutches } \\
\text { from father-son } \\
\text { mean/individual } \\
\text { first clutches }\end{array}$ & 77 & $-0.06 \pm 0.26$ & $0.36 \pm 0.26$ & $-0.20 \pm 0.22$ & $0.32 \pm 0.21$ \\
$\begin{array}{l}\text { B. Vlieland } \\
\text { from mother-daughter } \\
\text { (mean/individual) } \\
\text { first clutches only } \\
\text { from mother-daughter }\end{array}$ & 54 & $0.26 \pm 0.36$ & $0.82 \pm 0.24$ & $0.28 \pm 0.30$ & $0.72 \pm 0.30$ \\
$\begin{array}{l}\text { all combinations } \\
\text { first clutches only } \\
\text { from mother-daughter }\end{array}$ & 110 & $-0.10 \pm 0.22$ & $0.54 \pm 0.14$ & $0.12 \pm 0.20$ & $0.36 \pm 0.18$ \\
$\begin{array}{l}\text { all combinations } \\
\text { first \& second clutches } \\
\text { from father-son } \\
\text { mean/individual } \\
\text { first clutches }\end{array}$ & 54 & $0.02 \pm 0.16$ & $0.34 \pm 0.10$ & $0.20 \pm 0.14$ & $0.24 \pm 0.12$ \\
\hline
\end{tabular}

\section{Results}

Seven different repeatability values for each of four traits for the Hoge Veluwe population and the Vlieland population are given in Table 1. The repeatabilities for a combination of first and second clutches produced in April and June respectively, are similar to those comprising first clutches only, on Hoge Veluwe and on Vlieland in 1977. Apparently, the difference in environmental conditions between April and June has no strong systematic effect.

In years with a low repeatability from first to second clutches, females laying small eggs tend to increase their egg dimensions more than those that lay large eggs in the first clutch (Fig. 8).

The repeatability for shape is higher than for the other traits, both in Vlieland and in Hoge Veluwe. It is so high that it can be of practical use in deciding whether a particular first and repeat or second clutch can be attributed to one female. For instance, in 1978 a clutch of 21 eggs was observed in Hoge Veluwe, in which the numbers 10-16 were very different in shape from the numbers 1-9 and
17-21, while the first and the last group were very similar. A gap of two days was observed between eggs 9 and eggs 10. It is almost certain that this clutch was produced by at least two females. This clutch was excluded from the analysis.

There is a clear difference between the repeatabilities of males and females. Although the numbers of males with different partners are small, the mean of the repeatability values are close to zero for all traits.

Heritability estimates are given in Table 2. Three different ways of calculation are given for the female comparisons. While the results are very similar for Hoge Veluwe, there are considerable differences between estimates from Vlieland, except for shape. In the first estimate average egg characteristics per female are used. In the second estimate every clutch of the mother is compared with every first clutch of a daughter, while in the third estimate second clutches are also included. Some mother-daughter combinations are presented several times. The comparisons are only independent with respect to the variance caused by temporal environmental variation, which will affect 

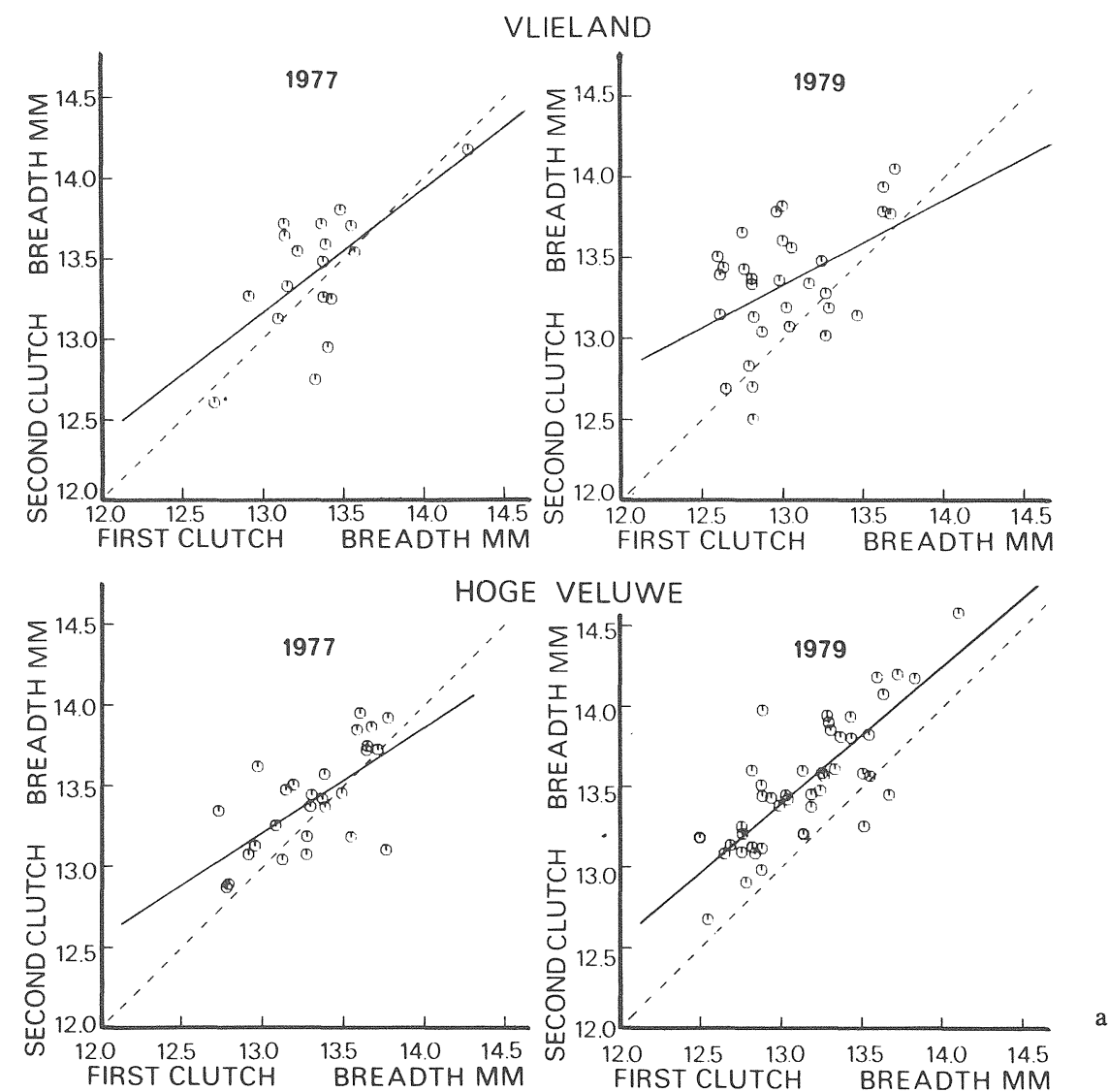

Fig. $8 a-b$. The relation between egg dimensions of first and those of second clutches of the same female: (a), median egg breadth; - (b) egg volume. Data from Vlieland and Hoge Veluwe, 1977 and 1979. The corresponding repeatability values are given in Table 1. Broken lines connect equal values for first and second clutches, drawn lines are the linear regressions.

the reliability of the standard errors. The first estimate is probably the most reliable, but see discussion.

In the father-son comparisons there is a positive regression for breadth. However in all explanations for such a regression, i.e. an influence on the egg size of the partner, site tenacity or assortative mating, a positive repeatability of males is expected. Taking together the repeatabilities of first clutches and the heritabilities based on mean values of first clutches, the male resemblances are at the most a fraction of the female resemblances.

For egg length and shape on Vlieland the motherdaughter resemblance is considerably less than the repeatability. These estimates are sensitive to rare events with a large effect. These low values are largely due to one female, which is also responsible for the low repeatability for breadth (and volume) in 1978. Apart from such rare events, about $60-80 \%$ of the total phenotypic variance can be attributed to genetic variance.

\section{Discussion}

\section{Genetic variation}

The total phenotypic variation in egg dimensions is the result of both genetic differences between individuals and variation in environmental conditions. The influence of the environmental variation on egg size can be seen from the difference in repeatability from first to second clutch in the three years (Table 1, Fig. 8). In 1979 the eggs in second clutches are larger than in first clutches, both on Vlieland and Hoge Veluwe, while there is 

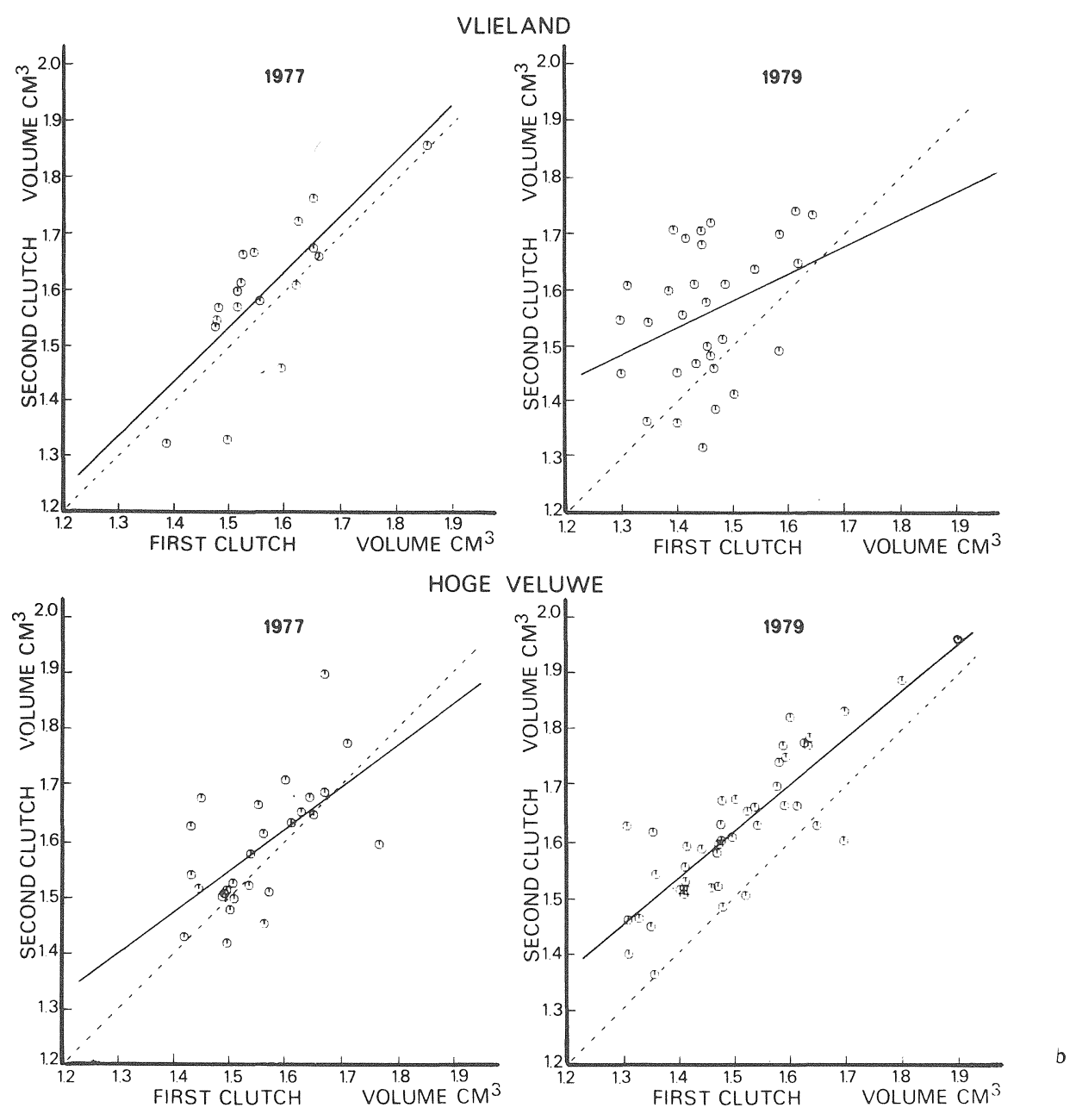

Fig. $8 b$. cf. legend of Figure 8 a.

hardly a difference in 1977, and 1978 is intermediate. The proportion of females making a second clutch however was different, about 1 in 6 in 1977,1 in 4 in 1978 and 1 in 2 in 1979, both on Vlieland and Hoge Veluwe. This might be explained by assuming that if the food situation is favourable more females lay a second clutch and the difference in egg size between first and second clutch increases.

However, in the few females from Vlieland of which egg dimensions are known from first and second clutches in 1978 and 1979 the larger increase in 1979 results from smaller eggs in first clutches in that year, while eggs in second clutches are very similar in size in both years. So, in fact, the high proportion of second clutches in 1979 is not an indication of good conditions during the laying period of second clutches but goes along with unfavourable conditions during the laying period of the first clutch. The occurrence of conditions leading to small eggs in first clutches in 1979 also explains why on Vlieland the heritability estimates comparing every clutch of the daughter with every clutch of the mother are much lower than those based on mean values per individual.

It is remarkable that the heritability values for egg volume in the Hoge Veluwe population $\left(\mathrm{h}^{2}=\right.$ $0.66 \pm 0.24, \mathrm{n}=60$ ) and in the Vlieland population $\left(\mathrm{h}^{2}=0.72 \pm 0.30, \mathrm{n}=54\right)$ are very close to the heritabilities for egg weight of Great Tits near Oxford $\left(h^{2}=0.72 \pm 0.22, n=81\right.$; Jones, 1973) and for egg volume in a population near Oulu in Finland $\left(\mathrm{h}^{2}=0.86 \pm 0.29, \mathrm{n}=45\right.$; Ojanen et al., 1979). In both studies the good agreement between the repeatability values and twice the motherdaughter regression (Jones used the correlation) is 
the sole argument for attributing the resemblance to genetic factors. This is insufficient to eliminate environmental heterogeneity with similar environments, either during growth or at the time of laying, for mother and daughter as a cause for resemblance. The low values for the male repeatability and son-father resemblance in our data suggest that spatial environmental heterogeneity is unimportant within our populations. The low value for male repeatability also shows that assortative mating with respect to a character correlated with egg-size genes is not present.

Marks (1978) found that in chicken the sperm volume produced by males is influenced by genes that also have an effect on daily egg mass production (egg number $\times$ egg weight) by females. This suggests that the attribution of resources to the reproductive organs is partly under genetic control.

On anatomical and physiological grounds it is attractive to suppose that if egg breadth and egg volume are under genetic control, egg length and egg shape result from the combination (cf. Table 2).

However, this would be in conflict with the fact that in nine of the ten series of female repeatabilities the value for shape is higher than that for the other traits. This constancy of shape can be explained by assuming that it is not the width but the expansibility of the oviduct that is under genetic control, breadth would then be the result of volume and shape. Figure 6 suggests that in large eggs the available material can be distributed in different ways, either in long and narrow or in short and broad eggs. This might be due to variation, mainly between females, of the expansibility of the oviduct. That this expansibility of the oviduct does have an environmental or a random component is shown by the negative correlation of length and breadth within clutches with large eggs.

\section{Selective importance}

Egg shape has no clear functional significance in the Great Tit. There are several aspects of egg volume with selective implications. Hatchling weight is highly correlated with fresh egg weight in the Great Tit (Schifferli, 1973) as well as in other species (e.g. Ankney, 1980; Bryant, 1975, 1978). Schifferli (1973) found that light hatchlings stay behind in growth, but the difference in fledgling weight was much smaller than halfway in the nestling period. If growth is not looked at as a function of age, but as a function of size, the difference between large and small hatchlings largely disappears. However, this applies to favourable conditions only. If there is a shortage of food, the smaller nestling(s) will presumably die first. Variation in egg size within clutches will have an effect through competition between nestlings. For differences between clutches this is irrelevant but larger hatchlings have an advantage over smaller ones in their ability to survive longer without food (e.g. Ankney, 1980; Bryant, 1978). During heavy rain Great Tit parents suspend all feeding activities. Nestling mortality is correlated with the a mount of rainfall during the day (Heynen, unpubl.). This could provide a selective force in favour of large eggs, large nestlings being more able survive periods without being fed. On the other hand selection for small eggs might result from benefits to the female investing less energy in egg formation. We have insufficient data to analyse net selection.

\section{The causes of variation}

In many species the variation in egg dimensions within a clutch is less than between clutches of different females (e.g. Kendeigh et al., 1956, 1975; Väisänen, 1977; Väisänen et al., 1972). Terns and gulls are a notable exception, their third egg is smaller, and the difference between the first two and the third egg is larger than the variation between clutches for the first two or third eggs (Barth, 1967; Cochfeld, 1977; Ricklefs et al., 1978).

The presence of genetic variation for egg size in the population tends to decrease the ratio of the variance within clutches and the variance between clutches of different females. Nevertheless, a relatively small variation within clutches is not necessarily a consequence of the presence of genetic variation. Eggs in one clutch may be similar because they have been laid under similar environmental conditions.

One may divide the environmental variation acting on egg size into a number of components:

(1) variation in conditions from day to day,

(2) variation in conditions from week to week,

(3) variation in conditions over months,

(4) variation in conditions over years,

(5) spatial heterogeneity, 
(6) lasting effects of conditions during growth of the female.

Within clutches, only the first source of environmental variation is represented as such, while 2 to 6 together with genetic variation are present in between clutch variation.

In our repeatabilities, in which clutch medians were used the first component is excluded, while the environmental variation consists mainly of component 3 and 4 . The fourth component (together with 5 and 6) is the relevant one for a prediction of offspring values from parental values. If this source of environmental variation is relatively large then the change in population mean brought about by a given amount of selection will be relatively small. The variation in this component (that is the extent to which years are different) might be studied by looking at the repeatability, for which data are more easily obtained than data for the motherdaughter regression. Such a study of variation in repeatability values would be indicative for variability in the heritability.

It might be argued that selection for egg size is strong only under bizarre environmental conditions, while the heritability under such conditions is probably much lower than the heritability under average conditions, since the heritability is a proportion of the total variation. If this is indeed the case then the high heritability values obtained would not indicate that the response to natural selection will immediately be large. In this argument it is assumed that the conditions at the time of egg formation and the time of selection are similar. However selection and egg formation do not coincide. Selection will act mostly on the nestlings and occurs at least a fortnight (i.e. the incubation period) later than the formation of the last egg. Direct or indirect (through food availability) effects of weather are probably of major importance both at the time of egg formation and at the time when differential mortality between hatchlings from eggs of different size occurs. In our climate there is no constancy in weather conditions over periods of weeks. Therefore the high values for the heritability of egg dimensions indicate that selection will result in rapid change of the population mean, when the environment undergoes a more permanent change.

\section{Acknowledgements}

This study made use of egg measurements and data on the breeding biology collected by H. M. van Eck, D. Westra and many others. We gratefully acknowledge the help of M. Nederlof and J. Visser in setting up and maintaining the data base. We thank J. den Boer-Hazewinkel and G. de Jong for many helpful discussions. We thank J. W. C. Spierenburg who constructed the volumeter, D. Smit and C. Strijland who prepared the figures, E. Kool and W. Wind who typed the manuscript. The investigations were supported by the Foundation for Fundamental Biological Research (BION), which is subsidized by the Netherlands Organization for the Advancement of Pure Research (Z.W.O.)

\section{References}

Ankney, C. D., 1980. Egg weight, survival and growth of lesser snow goose goslings. J. Wildl. Mgmt 44: 174-182.

Baker, C. M. A., 1960. The genetic basis of egg quality: a review of the literature. Br. Poult. Sci. 1: 3-16.

Baten, W. D. \& Henderson, E. W., 1941. Relations of weights and volumes of eggs to measurements of long and short axes. Poult. Sci. 20: 556-564.

Barth, E. K., 1953. Calculation of egg-volume on loss of weight during incubation. Auk 70: 152-159.

Barth, E. K., 1967. Egg dimensions and laying dates of Larus marinus, L. argentatus, L. fuscus, and L. canus. Nytt. Mag. Zool. 15: 5-34.

Bryant, D. M., 1975. Breeding biology of house martins Delichon urbica in relation to aerial insect abundance. Ibis 117: $180-216$.

Bryant, D. M., 1978. Environmental influences on growth and survival of nestling house martins Delichon urbica. Ibis 120: 271-283.

Dhondt, A. A., 1970. De regulatie der aantallen in Gentse koolmeespopulaties (Parus major L.). Thesis, Ghent.

Dunn, E. H., Hussell, D. J. T., \& Ricklefs, R. E., 1979. The determination of incubation stage in starling eggs. BirdBanding 50: 114-120.

Falconer, D. S., 1960. Introduction to quantitative genetics Oliver \& Boyd, Edinburgh \& London.

Festing, M. F. \& Nordskog, A. W., 1967. Response to selection for body weight and egg weight in chickens. Genetics 55: 219-231.

Gochfeld M, 1977. Intraclutch egg variation: The uniqueness of the common tern's third egg. Bird-Banding 48: 325-332.

Hoyt, D. F., 1976. The effect of shape on the surface-volume relationships of birds eggs. Condor 78: 343-349. 
Jaffé, W. P., 1966. Egg production, body weight and egg quality characters; their heritability and the correlations between them. Br. Poult. Sci. 7: 91-98.

Jones, P. J., 1973. Some aspects of the feeding ecology of the great tit Parus major L. Ph. D. thesis, Oxford.

Kendeigh, S. C., 1975. Effect of parentage on egg characteristics. Auk 92: 163-164.

Kendeigh, S. C., Kramer, T. C. \& Hamerstrom, P., 1956. Variation in egg characteristics of the house wren. Auk 73: 42-65.

Kluyver, H. N., 1951. The population ecology of the great tit, Parus major L. Ardea 39: 1-135.

Kluyver, H. N., 1971. Regulation of numbers in populations of great tits (Parus major) pp. 507-523 in: Dynamics of populations, P. J. den Boer \& G. R. Gradwell (eds.) Pudoc Wageningen.

Kluyver, H. N., Van Balen, J. H., \& Cavé, A. J., 1977. The occurrence of time-saving mechanisms in the breeding biology of the great tit, Parus major. pp. 153-169 in: Evolutionary Ecology, B. Stonehouse and C. Perrins (eds.), MacMillan Press, London and Basingstoke.

Koskimies, J., 1957. Variations in size and shape of eggs of the velvet scoter, Melanitta fusca. Archs Soc. Vanamo 12: 58-69.

Lack, D., 1966. Population studies of birds. Clarendon Press, Oxford.

Lack, D., 1968. Ecological adaptations for breeding in birds. Methuen, London.

Langvatn, R., 1972. Field measurements of the volume of small mammal organs. Oikos 23: 142-144.

Lewontin, R. C., 1974. The genetic basis of evolutionary change. Columbia, New York \& London.

Manning, T. H., 1978. Measurements and weights of eggs of the Canada goose, Branta canadensis, analyzed and compared with those of other species. Can. J. Zool. 56: 676-687.

Marks, H. L., 1978. Possible relationships between packed sperm volume and egg mass in domestic fowl. Experientia 34: 443-444.

Myhrberget, S., 1977. Size and shape of eggs of willow grouse Lagopus lagopus. Orn. Scand. 8: 39-46.

Nice, M. M., 1937. Studies in the life history of the song sparrow, vol. I. Trans. Linn. Soc. N-Y 4: 1-247.

Ojanen, M., Orell, \& Väisänen, R. A., 1979. Role of heredity in egg size variation in the great tit Parus major and the pied flycatcher Ficedula hypoleuca. Orn. Scand. 10: 22-28.
Perrins, C. M., 1979. British tits. Collins, London.

Ricklefs, R. E., Hahn, D. C., \& Montevecchi, W. A., 1978. The relationship between egg size and chick size in the laughing gull and Japanese quail. Auk 95: 135-144.

Romanoff, A. L. \& Romanoff, A. J., 1949. The avian egg. Wiley \& Sons, New York.

Schifferli, L., 1973. The effect of egg weight on the subsequent growth of nestling great tits Parus major. Ibis 115: 549-558.

Stonehouse, B., 1966. Egg volumes from linear dimensions. Emu 65: 227-228.

Svensson, B. W., 1978. Clutch dimensions and aspects of the breeding strategy of the chaffinch Fringilla coelebs in northern Europe: a study based on egg collections. Orn. Scand. 9: 66-83.

Väisänen, R. A., 1969. Evolution of the ringed plover (Charadrius hiaticula L.) during the last hundred years in Europe. Ann. Acad. sci. fenn. series A. IV. biologica 149: $1-90$.

Väisänen, R. A., 1974. Timing of waterfowl breeding on the Krunnit Islands, Gulf of Bothnia. Ornis fenn. 51: 61-84.

Väisänen, R. A., 1977. Geographic variation in timing of breeding in size in eight European species of waders. Ann. zool. fenn. 14: 1-25.

Väisänen, R. A., Hilden, O., Soikkeli, M.\& Vuolanto, S., 1972. Egg dimension variation in five wader species: the role of heredity. Ornis fenn. 49: 25-44.

Van Balen, J. H., 1973. A comparative study of the breeding ecology of the great tit Parus major in different habitats. Ardea 61: 1-93.

Van Noordwijk, A. J., Van Balen, J. H. \& Scharloo, W., 1980. Heritability of ecologically important traits in the great tit. Ardea 68: 193-203.

Van Noordwijk, A. J., Van Balen, J. H. \& Scharloo, W., 1981a. Genetic and environmental variation in clutch size of the great tit. Neth. J. Zool., in press.

Van Noordwijk, A. J., Van Balen, J. H., \& Scharloo, W., 1981 b. Genetic variation in the timing of reproduction in the great tit. Oecologia, in press.

Van Noordwijk, A. J. \& Scharloo, W., 1981. Inbreeding in an island population of the great tit. Evolution, in press.

Webber, M. I., 1975. Some aspects of the non-breeding population dynamics of the great tit (Parus major). Thesis, Univ. Oxford. 